\title{
Renal insufficiency was correlated with 2-year mortality for rural female patients with ST-segment elevation acute myocardial infarction after reperfusion therapy: a multicenter, prospective study
}

\author{
Yuan Gao ${ }^{1 *}$, Daming Jiang ${ }^{2}$, Bo Zhang ${ }^{3}$, Yujiao Sun ${ }^{4}$, Lina Ren ${ }^{1}$, Dandan Fan ${ }^{1}$ and Guoxian Qi ${ }^{1}$
}

\begin{abstract}
Background: Renal insufficiency (RI) following ST-segment elevation acute myocardial infarction (STEMI) is associated with a worse clinical prognosis. We investigated the impact of RI on long-term mortality in rural female patients with STEMI and evaluated prognostic factors.

Methods: A prospective cohort study of 436 consecutive rural female patients who were successfully treated with reperfusion therapy for STEMI between May 2009 and August 2011 in secondary care hospitals in Liaoning province northeastern China and followed up for 2 years. Patients were divided into three groups by estimated glomerular filtration rate (eGFR): Normal group, eGFR $\geq 90 \mathrm{~mL} / \mathrm{min} / 1.73 \mathrm{~m}^{2}$ ( $n=233$ ). Moderate group, eGFR 60-90 mL/min/ $1.73 \mathrm{~m}^{2}(n=108)$. Rl group, eGFR $<60 \mathrm{~mL} / \mathrm{min} / 1.73 \mathrm{~m}^{2}(n=95)$. The primary outcome was 2-year mortality.

Results: During follow-up (mean $741 \pm 118$ days), the RI group had a significantly higher mortality than the other groups ( $24.21 \%$ vs. $6.87 \%$ and $10.19 \%, p<0.001)$. The Rl group had significantly higher hospital mortality $(7.37 \%$ $p=0.045$ vs. Normal group). Rl increased the risk of hospital mortality (hazard ratio (HR) 1.832, 95 \% Cl 1.017-3.091, $p=0.033$ ), and increased the risk of 2-year mortality (HR 3.872, $95 \% \mathrm{Cl} 2.004-6.131, p<0.001$ ). Multivariate analysis showed eGFR $<90 \mathrm{ml} / \mathrm{min} / 1.73 \mathrm{~m}^{2}$ and age $\geq 75$ years as independent predictors of mortality at 2 years. In detail these were eGFR 60-90 ml/min/1.73 $\mathrm{m}^{2}$ with HR 2.081, 95\%Cl 1.250-2.842, $p<0.001$; eGFR $<60 \mathrm{ml} / \mathrm{min} / 1.73 \mathrm{~m}^{2}$ with HR 3.872, 95\%Cl 2.004-6.131, $p<0.001$; age $\geq 75$ with HR 1.461, 95\%Cl 1.011-1.952, $p=0.024$.
\end{abstract}

Conclusions: RI had a powerful correlation with long-term mortality for rural female patients with STEMI after reperfusion therapy.

Keywords: ST-segment elevation, Myocardial infarction, Renal insufficiency, Risk factors

\section{Background}

At present the incidence of chronic kidney disease is rapidly increasing [1]. Nearly $30 \%$ of patients with STsegment elevation acute myocardial infarction (STEMI) have combined renal insufficiency (RI) [2]. Widely used early reperfusion therapy, including emergency primary percutaneous coronary intervention $(\mathrm{PCI})$ or thrombolysis

\footnotetext{
* Correspondence: plateau1216@163.com

'Department of Cardiology, First Affiliated Hospital of China Medical

University, Shenyang, Liaoning 110001, China

Full list of author information is available at the end of the article
}

therapy has beneficial effects for STEMI [3, 4]. However, RI following STEMI is associated with a worse clinical prognosis [5-7], a 6 to 11-fold increase in hospital risk of death [8], and a 1.76 - to 6.18-fold 7month risk of death [6]. Unfortunately, most STEMI patients with RI are excluded from randomized trials. Renal insufficiency may lead to alteration in lipid metabolism, vascular endothelial injury and dysfunction, trigger the inflammatory response, coagulation and oxidative stress and increase atherosclerosis, by the 
sympathetic, neurohormonal pathway and renin angiotensin aldosterone axis activation [9-11].

Most clinical studies into myocardial infarction involve only a minority of female patients. For example women accounted for $29.6 \%$ of the total enrolled patients in the Korea acute myocardial infarction registry study [7]. This is of concern because acute myocardial infarction mortality is higher in females than males and while there have been declines in the risk of death in men; the rate in women remains fairly constant [12]. The risk of in hospital mortality after primary PCI is also significantly higher for females than males [13], and female patients with STEMI show significantly greater death rates than males [14], with younger females at much higher risk than males of the same age [15].

In China the rates of mortality due to cardiac disease are growing, and while they are highest in urban areas, the rate in rural areas is increasing more rapidly [16]. Therefore, female patients with STEMI complicated by RI who reside in rural areas are an often neglected population that may be at high risk of death resulting from their condition. Little is known of the impact of RI on the prognosis in rural female patients with STEMI regardless of reperfusion therapy in Liaoning province in northeastern China.

The objective of this study was to determine the association between RI and the risk of death in STEMI patients successfully treated with PCI or thrombolytic therapy. We hypothesized that RI would be associated with higher 2-year mortality. The results of our prospective cohort study provide convincing evidence of this association in a real world situation.

\section{Methods}

\section{Subjects}

This was a prospective, multicenter study conducted at 16 hospitals in the Liaoning Province of northeast China from May 2009 to August 2011. The 16 hospitals were: First Affiliated Hospital, China Medical University; First Affiliated Hospital, Dalian Medical University; Changtu xian People's Hospital; Fuxin Mongolian Autonomous County People's Hospital; Yixian People's Hospital; Benxi Steel Company Hospital; Fushun Coal Mining Administration Hospital; Chaoyang Center Hospital; Fuxin Center Hospital; Zhuanghe Center Hospital; Wafangdian Center Hospital; Pulandian Center Hospital; Donggang Center Hospital; Dashiqiao Center Hospital; Zhangwu xian People's Hospital; Kuandian xian Center Hospital.

This study was conducted in accordance with the declaration of Helsinki, and was conducted with approval from the Ethics Committee of China Medical University. Written informed consent was obtained from all participants.

We enrolled 479 consecutive rural female STEMI patients from May 2009 to August 2011 from all of the centers. The inclusion criteria were: (1) STEMI was diagnosed according to European Society of Cardiology (ESC) criteria [3]; (2) it was the first time STEMI was diagnosed; (3) all patients were given primary PCI treatment within $12 \mathrm{~h}$ or thrombolytic therapy within $6 \mathrm{~h}$ after symptom onset. The exclusion criteria were: (1) acute myocardial infarction patients with acute kidney injury (AKI); (2) patients undergoing dialysis treatment. (3) patients whose non-infarct-related artery was treated during primary PCI; (4) PCI was undertaken after thrombolytic therapy.

Acute renal failure was diagnosed by an increase in serum creatinine levels of $50 \%$ or an absolute increase of $\geq 26.5 \mu \mathrm{mol} / \mathrm{l}$ in $48 \mathrm{~h} \mathrm{[17]}$.

Demographic and basic clinical data were obtained from all patients, which included age, gender, body mass index and cardiovascular risk factors. Additional clinical data including clinical laboratory tests, coronary imaging data, therapeutic strategies and adverse cardiac events were collected by trained personnel.

\section{eGFR measurement}

Kidney function was measured by estimated glomerular filtration rate (eGFR), calculated using the Chronic Kidney Disease Epidemiology Collaboration (CKD-EPI) Modification of Diet in Renal Disease (MDRD) equation [18] [CKD-EPI formula If female and if serum creatinine (Scr) $\leq 0.7 \mathrm{mg} / \mathrm{dL}$ :

$$
\begin{aligned}
\mathrm{CKD}-\mathrm{EPI}= & 144 \times \mathrm{Scr}(\mathrm{mg} / \mathrm{dL}) / 0.7^{-0.329} \\
& \times 0.993^{\text {age }(\text { years })}
\end{aligned}
$$

If female and if Scr $>0.7 \mathrm{mg} / \mathrm{dL}$ :

$$
\begin{aligned}
\mathrm{CKD}-\mathrm{EPI}= & 144 \times \mathrm{Scr}(\mathrm{mg} / \mathrm{dL}) / 0.7^{-1.209} \\
& \times 0.993^{\text {age }(\text { years })} .
\end{aligned}
$$

Renal insufficiency (RI) was defined as eGFR $<60 \mathrm{~mL} /$ $\mathrm{min} / 1.73 \mathrm{~m}^{2}$ according to the Kidney Disease: Improving Global Outcomes (KDIGO) guidelines [19] eGFR were calculated by the Scr examination results immediately after admission.

The patients were divided into 3 groups based on their eGFR values; the Normal group (high eGFR group, eGFR $\left.\geq 90 \mathrm{~mL} / \mathrm{min} / 1.73 \mathrm{~m}^{2}, n=233\right)$, the Moderate group (middle eGFR group, $60 \mathrm{~mL} / \mathrm{min} \cdot \mathrm{m}^{2}<\mathrm{eGFR}$ $\left.<89 \mathrm{~mL} / \mathrm{min} / 1.73 \mathrm{~m}^{2}, n=108\right)$ who had moderate RI, and the RI group (low eGFR group, eGFR $<60 \mathrm{~mL} / \mathrm{min} /$ $\left.1.73 \mathrm{~m}^{2}, n=95\right)$.

\section{Successful PCI}

PCI was considered to be successful if the infarct-related artery residual stenosis was $<10 \%$, and the Thrombolysis in Myocardial Infarction (TIMI) flow level reached 3 [20]. All patients were estimated immediately after PCI. 


\section{Successful thrombolytic therapy}

1.5 million Units of urokinase were administrated to patients by intravenous infusion within $30 \mathrm{~min}$ for thrombolytic therapy.

Thrombolytic therapy was considered successful if more than 2 of 4 criteria were met [9]: ST segment resolved by $\geq 50 \%$ by electrocardiogram (ECG) within $2 \mathrm{~h}$, chest pain disappeared within $2 \mathrm{~h}$; reperfusion arrhythmia occurred; serum myocardial enzyme peaks were detected in advance.

\section{Medication}

All patients received the recommended standard management for STEMI, including $300 \mathrm{mg}$ loading dose of aspirin and clopidogrel after admission, aspirin, clopidogrel, low-molecular-weight heparin, beta-blockers, statins and angiotensin-converting enzyme (ACE) inhibitors/ angiotensin receptor antagonist (ARB) as appropriate. The details of the medications are included in Appendix 1.

\section{Definition of risk factors}

Abnormal body mass index (BMI) was defined as BMI $\geq$ $25 \mathrm{~kg} / \mathrm{m}$ [2, 21]. Diabetes was diagnosed by previous medical history or fasting glucose $\geq 7.0 \mathrm{mmol} / \mathrm{L}$ and/or $2 \mathrm{~h}$ plasma glucose level $\geq 11.1 \mathrm{mmol} / \mathrm{l}$ (measured after $75 \mathrm{~g}$ oral glucose load). Hypertension was diagnosed by previous medical history or systolic blood pressure $\geq$ $140 \mathrm{mmHg}$ and/or diastolic blood pressure $\geq 90 \mathrm{mmHg}$ after admission. Hypercholesterolemia was diagnosed by previous medical history or low-density lipoprotein (LDL) cholesterol $\geq 2.6 \mathrm{mmol} / \mathrm{L}$ and/or non high-density lipoprotein (HDL) cholesterol $\geq 3.3 \mathrm{mmol} / \mathrm{L}$. Definition of contrast-induced nephropathy (CIN) was an increase in serum creatinine $\geq 0.5 \mathrm{mg} / \mathrm{dL}$, occurring $48 \mathrm{~h}$ after exposure to contrast media [22]. Current smoker was defined as smoking $>300$ cigarettes/year.

\section{Outcomes}

Major adverse cardiac events (MACE) included: death, recurrent myocardial infarction, target vessel revascularization and stroke.

Key bleeding end points were analyzed on the basis of global use of strategies to open occluded coronary arteries (GUSTO) criteria [23].

CIN, contrast-induced nephropathy was defined as either a greater than $25 \%$ increase of serum creatinine or an absolute increase in serum creatinine of $0.5 \mathrm{mg} / \mathrm{dL}$ [24].

\section{Clinical examination and laboratory analysis}

Patients underwent physical examination, ECG examination and fasting blood biochemical examination after admission including Scr, serum creatine kinase MB (CKMB), and cardiac troponin I (cTNI). Patients were examined for myocardial necrosis markers and by ECG once every $8 \mathrm{~h}$ in $72 \mathrm{~h}$, then every $24 \mathrm{~h}$ they were examined again. Blood leukocyte counts were examined $24 \mathrm{~h}$ after admission and echocardiography $48 \mathrm{~h}$ after admission.

To ensure the standard of data collection, laboratory procedures, data management and coordination between the multiples centers involved in the study was up to our quality control all the clinicians involved in this study received uniform training before the research began.

\section{Follow up}

The patients were followed up by telephone for 2 years; once per year; by the same doctor.

\section{Statistical method}

Categorical data were expressed with absolute numbers and percentages and analyzed using the $\chi^{2}$ test. Continuous data with normal distribution were described with mean and standard deviation (SD) and median and interquartile range (IQR; 25th to 75th). Data among groups were compared using ANOVA. Further StudentNewman-Keuls (SNK) analyses were performed between the three groups. Non-normally distributed data among groups were compared using rank test.

Corresponding Kaplan-Meier curves with the logrank test were constructed. Univariate analysis of eGFR, Scr, Microalbuminuria, age, gender, diabetes, hypertension, hyperlipidemia, Killip class, heart rate (HR), ejection fraction (EF), white blood cell (WBC) counts, and medication treatment were performed to determine the predictors for mortality. Multiple Cox proportional hazard model was used to estimate associations between significant factors identified in the univariate analysis. Hazard ratios (HR) and $95 \%$ confidence intervals $(\mathrm{CI})$ were calculated and $\mathrm{p}$ value $<0.05$ was considered statistically significant. All analyses were performed using SPSS version 19.0 (SPSS Inc., Chicago, IL, USA).

\section{Results}

The flowchart showing inclusion of patients in the study is presented in Fig. 1. In total 479 patients were enrolled in the study, 24 from these were excluded including 8 patients with incomplete data, 4 for whom clinical data were incomplete and 4 whose laboratory data were incomplete. Thus, 455 patients were included and 19 patients were lost to follow up. Finally 436 patients were included in the study 233 in the Normal group, 108 in the Moderate group, and 95 in the RI group (Fig. 1).

\section{Study sample and characteristics}

The mean follow-up period was $741 \pm 118$ days. Among the 436 individuals in the final cohort, the mean age was 67.52 years, and $35.78 \%$ had diabetes (Table 1). Elderly 


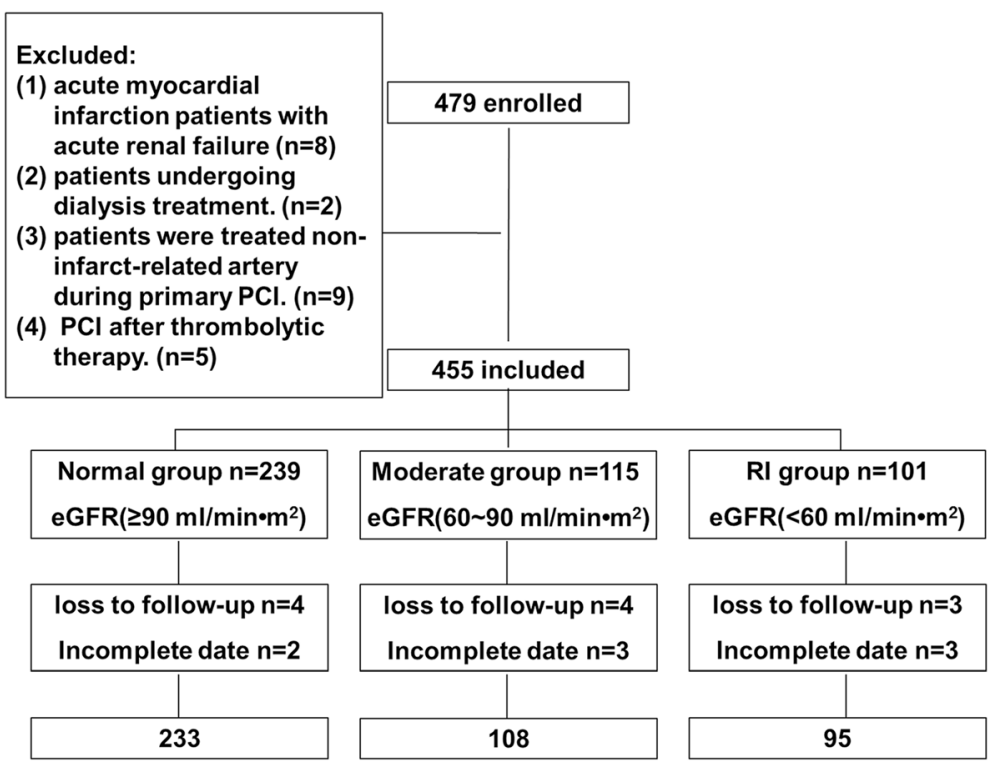

Fig. 1 Flow chart of the selection of the study population and allocation into groups according to estimated glomerular filtration rate

patients and those with hypertension and diabetes accounted for a high proportion of patients in the RI group. Median symptom to door time, door to balloon time and door to needle time were 183, 134 and $56 \mathrm{~min}$, respectively. In the three groups the mean ages were $61.11 \pm 8.42$ years in the Normal group, $64.08 \pm 6.91$ years in the Moderate group and $75.57 \pm 7.53$ years in the RI group with a significant difference between all of the groups $(p<0.05)$. The diabetes rates were $29.61 \%$ in the Normal group, $37.96 \%$ in the Moderate group and $48.42 \%$ in the RI group with a significant difference between the Normal and RI groups $(p<0.05)$. The hypertension rates were $32.19 \%$ in the Normal group $44.44 \%$ in the Moderate group and $52.63 \%$ in the RI group with a significant difference between the Normal and RI group $(p<0.05)$. There were higher proportions in the RI group of Killip $\geq 2$ at $21.05 \%$ compared to $9.26 \%$ $(p<0.05)$ in the Moderate group and $9.01 \%,(p<0.05)$ in the Normal group, longer hospital stay at $12.05 \pm$ 5.74 days compared to $8.36 \pm 5.11$ days $(p<0.05)$ in the Moderate group and $8.53 \pm 4.78$ days $(p<0.05)$ in the Normal group, low EF values at $44.38 \pm 13.05 \%$ compared to $48.92 \pm 14.02 \%(p<0.05)$ in the Moderate group and $50.11 \pm 13.60 \%(p<0.05)$ in the Normal group, high Scr values at $116.67 \pm 59.01 \mathrm{mmol} / \mathrm{l} \mathrm{com}-$ pared to $85.47 \pm 44.90 \mathrm{mmol} / \mathrm{l}(p<0.05)$ in the Moderate group and $78.12 \pm 31.13 \mathrm{mmol} / \mathrm{l}(p<0.05)$ in the Normal group, and cTnI peak at $45.33 \pm 15.26 \mathrm{ng} / \mathrm{ml}$ compared to $30.19 \pm 18.73 \mathrm{ng} / \mathrm{ml}(p<0.05)$ for the Moderate group and $31.06 \pm 16.28 \mathrm{ng} / \mathrm{ml}$ for the Normal group $(p<0.05)$ (Table 1$)$. There were 298 patients who underwent primary PCI and 138 thrombolytic therapy.

\section{Clinical outcomes}

The mortality rates of the patients in the Normal group, Moderate group and RI group were $1.72 \%$, $3.7 \%$, and $7.37 \%$, respectively, during hospitalization. Patients in the RI group had a significantly higher mortality rate compared with Normal group during hospitalization $(p=0.045)$. There were no significant differences in RMI, TVR, stroke and bleeding between the three groups. In-hospital MACE developed more frequently in the patients in the RI group compared with Normal group $(p=0.022)$. But there was no significant difference in the incidence of CIN (Table 2).

A similar trend was observed during 1 year of follow up after hospital discharge. Patients in the RI group had a significantly higher mortality rate compared with those in the Normal group ( $16.84 \%$ v.s.4.29\%, $p<0.001)$, and a significantly higher MACE rate compared with the other two groups $(p<0.001)$ (Table 2$)$.

During 2 years of follow up, patients in the RI group had a significantly higher mortality rate compared with the other two groups ( $24.21 \%$ v.s. $6.87 \%$ and $10.19 \%, p<$ $0.001)$. There were no significant differences in recurrent myocardial infarction (RMI), target vessel revascularization (TVR), stroke and bleeding between the three groups. Compared with the RI group respectively, the Moderate group and the Normal group had higher MACE rates 
Table 1 Baseline characteristics

\begin{tabular}{|c|c|c|c|c|c|}
\hline & Normal group $(n=233)$ & Moderate group $(n=108)$ & Rl group $(n=95)$ & $x^{2} / F$ & $p$ value \\
\hline Age (years) & $61.11 \pm 8.42$ & $64.08 \pm 6.91^{a}$ & $75.57 \pm 7.53^{\mathrm{ab}}$ & 114.59 & $<0.001$ \\
\hline BMI $\left(\mathrm{kg} / \mathrm{m}^{2}\right)$ & $24.51 \pm 4.49$ & $24.03 \pm 3.98$ & $23.95 \pm 5.08$ & 0.721 & 0.486 \\
\hline Killip $\geq 2$ & $21(9.01)$ & $10(9.26)$ & $20(21.05)^{\mathrm{ab}}$ & 10.297 & 0.006 \\
\hline $\mathrm{HR}(\mathrm{bpm})$ & $71.58 \pm 23.40$ & $73.29 \pm 19.17$ & $78.05 \pm 25.18$ & 2.823 & 0.061 \\
\hline Current smoker (\%) & $96(41.20)$ & $47(43.52)$ & $45(47.37)$ & 1.056 & 0.59 \\
\hline Diabetes (\%) & $69(29.61)$ & $41(37.96)$ & $46(48.42)^{a}$ & 10.686 & 0.005 \\
\hline Hypertention (\%) & 75 (32.19) & $48(44.44)$ & $50(52.63)^{a}$ & 13.145 & 0.001 \\
\hline Hyperlipidemia (\%) & 79 (33.91) & $36(33.33)$ & $29(30.53)$ & 0.799 & 0.671 \\
\hline Previous MI (\%) & $15(6.44)$ & $9(8.33)$ & $2(2.11)$ & 3.697 & 0.157 \\
\hline Previous PCI (\%) & $11(4.72)$ & $5(4.63)$ & $4(4.21)$ & 0.078 & 1 \\
\hline Previous stroke & $2(0.86)$ & $3(2.78)$ & $4(4.21)$ & 4.336 & 0.087 \\
\hline Peripheral vasculardisease (\%) & $3(1.29)$ & $1(0.95)$ & $1(1.05)$ & 0.261 & 1 \\
\hline Anterior and/or Lateral wall (\%) & $113(57.08)$ & $45(41.67)$ & $53(55.79)$ & 4.039 & 0.133 \\
\hline Inferior and/or Posterior wall & $105(45.06)$ & $60(55.56)$ & $40(42.11)$ & 4.437 & 0.109 \\
\hline Maximum ST segment elevation (mm) & $3.16 \pm 1.27$ & $2.95 \pm 1.08$ & $3.11 \pm 1.33$ & 1.072 & 0.345 \\
\hline Q wave & $96(41.20)$ & $38(35.19)$ & $41(42.11)$ & 1.573 & 0.455 \\
\hline \multicolumn{6}{|l|}{ Symptom to door time (min) } \\
\hline Median (25-75th) & $189.46(130.51-392.26)$ & $170.13(110.50-337.12)$ & $180.11(104.39-387.25)$ & 0.978 & 0.613 \\
\hline \multicolumn{6}{|l|}{ Door to balloon time (min) } \\
\hline Median (25-75th) & $123.42(91.35-210.92)$ & $135.56(80.49-198.55)$ & $142.6(98.53-228.11)$ & 3.071 & 0.215 \\
\hline \multicolumn{6}{|l|}{ Door to needle time (min) } \\
\hline Median (25-75th) & $58.21(28.20-110.83)$ & $50.55(31.02-126.02)$ & $63.48(32.01-130.44)$ & 4.335 & 0.114 \\
\hline Left ventricular ejection fraction (\%) & $50.11 \pm 13.60$ & $48.92 \pm 14.02$ & $44.38 \pm 13.05^{\mathrm{ab}}$ & 6.051 & 0.003 \\
\hline IABP use & $3(1.29)$ & $5(4.63)$ & $1(1.05)$ & 3.882 & 0.143 \\
\hline Successful PCl & $166(71.24)$ & $73(67.59)$ & $57(60.00)$ & 3.92 & 0.141 \\
\hline Successful thrombolysis & $40(17.17)$ & $21(19.44)$ & $18(18.95)$ & 0.314 & 0.855 \\
\hline Serum creatinine $(\mathrm{mmol} / \mathrm{l})$ & $78.12 \pm 31.13$ & $85.47 \pm 44.90$ & $116.67 \pm 59.01^{\mathrm{ab}}$ & 28.612 & $<0.001$ \\
\hline Peak troponin (ng/ml) & $31.06 \pm 16.28$ & $30.19 \pm 18.73$ & $45.33 \pm 15.26^{\mathrm{ab}}$ & 28.253 & $<0.001$ \\
\hline Hospitalization days & $8.53 \pm 4.78$ & $8.36 \pm 5.11$ & $12.05 \pm 5.74^{\mathrm{ab}}$ & 18.401 & $<0.001$ \\
\hline
\end{tabular}

$B M I$ body mass index, $H R$ heart rate, $M I$ myocardial infarction, $P C l$ percutaneous coronary intervention, IABP intra-aortic balloon pump acompared to Group A, $p<0.05$

${ }^{\mathrm{b}}$ compared to Group B, $p<0.05$

(36.11 \% v.s. $22.32 \%, 52.63 \%$ v.s. $22.32 \%, p<0.001)$ (Table 2).

During 2 years of follow-up, there were 1 case of moderate bleeding and 4 cases of minor bleeding in the RI group. There were 3 cases of minor bleeding in the other two groups, respectively.

Risk factors of $\mathbf{2}$ year mortality

Variables were analyzed by univariate analysis for significant factors for 2 year mortality and are presented in Table 3, this suggested that eGFR of less than $90 \mathrm{ml} / \mathrm{min} / 1.73 \mathrm{~m}^{2}$, may be a predictor of 2 year mortality as both $60-90 \mathrm{ml} / \mathrm{mim} / \mathrm{m}^{2}$ eGFR and
eGFR $<60 \mathrm{ml} / \mathrm{min} / 1.73 \mathrm{~m}^{2}$ were significant (both $p>$ $0.001)$. Age $\geq 75$ years was another significant factor $(p=0.049)$ as well as hypertension $(p=0.013)$, Killip class $\geq 2 \quad(p=0.023)$, and EF $<40 \quad(p=0.025)$. The Kaplan-Meier survival curves are depicted in Fig. 2. The survival rate of the RI group was significantly lower than in the other two groups (log-rank test, $p$ $<0.001)$.

Multivariate analysis then identified eGFR $<90 \mathrm{ml} / \mathrm{min} /$ $1.73 \mathrm{~m}^{2}$ and age $\geq 75$ years as independent predictors of mortality at 2 years. In detail these were eGFR $60-90 \mathrm{ml} /$ $\mathrm{min} / 1.73 \mathrm{~m}^{2}$ with $\mathrm{HR} 2.081,95 \% \mathrm{CI} 1.250-2.842, p<$ 0.001 ; eGFR $<60 \mathrm{ml} / \mathrm{min} / 1.73 \mathrm{~m}^{2}$ with $\mathrm{HR} 3.872,95 \% \mathrm{CI}$ 
Table 2 Outcomes of patients according to eGFR group

\begin{tabular}{|c|c|c|c|c|c|}
\hline & $\begin{array}{l}\text { Normal group } \\
(n=233)\end{array}$ & $\begin{array}{l}\text { Moderate group } \\
(n=108)\end{array}$ & $\begin{array}{l}\text { Rl group } \\
(n=95)\end{array}$ & $x^{2}$ & $p$ value \\
\hline \multicolumn{6}{|l|}{ In hospital } \\
\hline MACE & $7(3.00)$ & $6(5.56)$ & $10(10.53)^{a}$ & 7.664 & 0.022 \\
\hline death & $4(1.72)$ & $4(3.70)$ & $7(7.37)^{a}$ & 6.127 & 0.045 \\
\hline Recurrent Ml & $2(0.86)$ & $1(0.93)$ & $1(1.05)$ & 0.472 & 1 \\
\hline TVR & 0 & $1(0.93)$ & $1(1.05)$ & 2.941 & 0.216 \\
\hline Stroke & 0 & 0 & 0 & & NS \\
\hline Bleeding & $1(0.43)$ & 0 & $1(1.05)$ & 1.403 & 0.45 \\
\hline CIN & 0 & $1(0.93)$ & $2(2.11)$ & 4.383 & 0.06 \\
\hline \multicolumn{6}{|l|}{ At 1-year follow-up } \\
\hline MACE & $35(15.02)$ & $24(22.22)$ & $36(37.89)^{\mathrm{ab}}$ & 20.734 & $<0.001$ \\
\hline death & $10(4.29)$ & $8(7.41)$ & $16(16.84)^{a}$ & 14.814 & $<0.001$ \\
\hline Recurrent Ml & $9(3.86)$ & $4(3.70)$ & $3(3.16)$ & 0.117 & 1 \\
\hline TVR & $12(5.15)$ & $9(8.33)$ & $12(12.63)$ & 5.519 & 0.063 \\
\hline Stroke & $1(0.43)$ & $2(1.85)$ & $1(1.05)$ & 2.02 & 0.424 \\
\hline Bleeding & $3(1.29)$ & $1(0.93)$ & $4(4.21)$ & 3.244 & 0.173 \\
\hline \multicolumn{6}{|l|}{ At 2-year follow-up } \\
\hline MACE & $52(22.32)$ & $39(36.11)^{a}$ & $50(52.63)^{a}$ & 29.275 & $<0.001$ \\
\hline death & $16(6.87)$ & $11(10.19)$ & $23(24.21)^{\mathrm{ab}}$ & 20.227 & $<0.001$ \\
\hline Recurrent Ml & $13(5.58)$ & $10(9.26)$ & $6(6.32)$ & 1.631 & 0.442 \\
\hline TVR & $17(7.30)$ & $12(11.11)$ & 13 (13.68) & 3.524 & 0.172 \\
\hline Stroke & $3(1.29)$ & $3(2.78)$ & $3(3.16)$ & 1.919 & 0.391 \\
\hline Bleeding & $3(1.29)$ & $3(2.78)$ & $5(5.26)$ & 4.275 & 0.109 \\
\hline
\end{tabular}

eGFR estimated glomerular filtration rate, $M I$ myocardial infarction, TVR target vessel revascularization, MACE major adverse cardiac events

${ }^{a}$ compared to Normal group, $p<0.05$

${ }^{\mathbf{b}}$ compared to Moderate group, $p<0.05$

Table 3 Univariate and multivariate analysis for prediction of 2-year mortality

\begin{tabular}{|c|c|c|c|c|c|c|}
\hline & \multicolumn{3}{|c|}{ Univariate } & \multicolumn{3}{|c|}{ Multivariate } \\
\hline & $\mathrm{HR}$ & $95 \% \mathrm{Cl}$ & $p$ value & $\mathrm{HR}$ & $95 \% \mathrm{Cl}$ & $p$ value \\
\hline \multicolumn{7}{|c|}{ eGFR ml/min/1.73 m² } \\
\hline$\geq 90$ & 1 & & & 1 & & \\
\hline $60-90$ & 2.911 & $1.295-3.731$ & $<0.001^{*}$ & 2.081 & $1.250-2.842$ & $<0.001^{*}$ \\
\hline$<60$ & 5.043 & $1.585-8.960$ & $<0.001^{*}$ & 3.872 & $2.004-6.131$ & $<0.001^{*}$ \\
\hline Age $\geq 75$ & 1.368 & $1.023-1.909$ & $0.049^{*}$ & 1.461 & $1.011-1.952$ & $0.024^{*}$ \\
\hline Diabetes & 1.332 & $0.727-1.936$ & 0.251 & & & \\
\hline Hypertension & 1.241 & $1.032-1.453$ & $0.013^{*}$ & 1.191 & $0.904-1.395$ & 0.114 \\
\hline Hyperlipidemia & 0.927 & $0.544-1.147$ & 0.690 & & & \\
\hline Killip $\geq 2$ & 1.593 & $1.032-2.301$ & $0.023^{*}$ & 1.131 & $0.781-1.893$ & 0.586 \\
\hline $\mathrm{EF}<40 \%$ & 1.227 & $1.012-1.447$ & $0.025^{*}$ & 0.905 & $0.451-1.060$ & 0.647 \\
\hline
\end{tabular}

Cl confidence interval, eGFR estimated glomerular filtration rate, EF ejection fraction, $H R$ hazard ratio ${ }^{*} p<0.05$ 


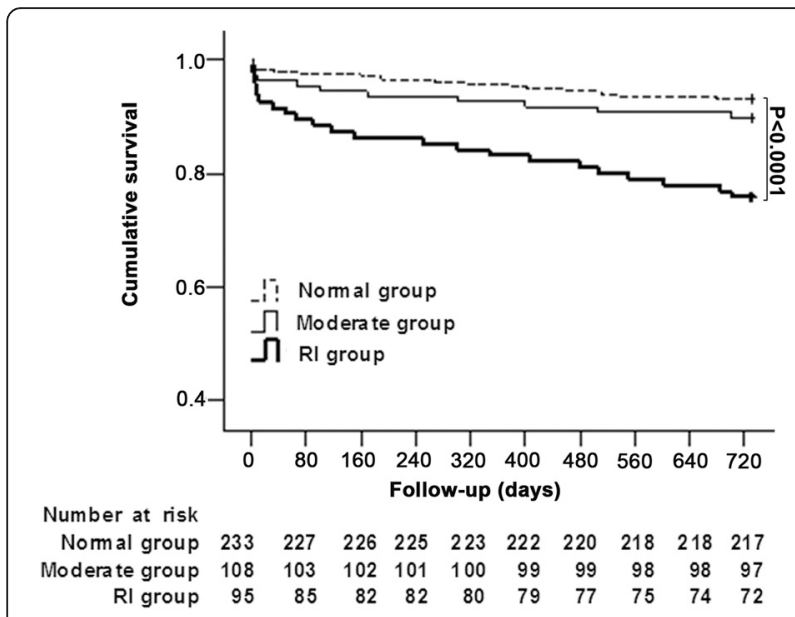

Fig. 2 Kaplan-Meier curve survival analysis of the three groups of patients to 2-year post treatment. A represents the Normal group, B represents the Moderate group and $C$ represents the RI group

2.004-6.131, $p<0.001$; age $\geq 75$ with $\mathrm{HR} 1.461,95 \% \mathrm{CI}$ $1.011-1.952, p=0.024$.

\section{Risk factors for in hospital mortality}

All variables were also included into univariate analysis to investigate the independent predictors for in hospital mortality. The independent predictors of mortality in hospital were eGFR $<60 \mathrm{ml} / \mathrm{min} / 1.73 \mathrm{~m}^{2}$ and Killip $\geq 2$ (Table 4). Further analysis of the significant factors by multiple cox proportional hazard modeling identified independent predictors of mortality. This showed that the independent predictors of hospital mortality were eGFR $<60 \mathrm{ml} / \mathrm{min} / 1.73 \mathrm{~m}^{2}$ [HR 1.832, $95 \%$ CI 1.017-3.091, $p$ $=0.033]$ and Killip $\geq 2$ [HR 1.340, $95 \%$ CI 1.012-1.647, $p=0.018]$.

\section{Discussion}

The aim of this study was to investigate the effect of RI on the mortality of female rural patients with STEMI. We demonstrated that the in hospitalization and 2-year mortality in the RI group $\left(<60 \mathrm{ml} / \mathrm{min} / 1.73 \mathrm{~m}^{2}\right)$ were significantly higher than in the other two groups. And RI (eGFR $<60 \mathrm{ml} / \mathrm{min} / 1.73 \mathrm{~m}^{2}$ ) was an independent predictor of in hospital and 2-year mortality in the female STEMI patients after emergency reperfusion therapy. Compared with the Normal group, there was a 1.8-fold higher risk of death during hospitalization, and 3.9-fold higher risk of 2-year mortality. In the Moderate group (60-89 $\left.\mathrm{ml} / \mathrm{min} / 1.73 \mathrm{~m}^{2}\right)$, there was a 2.1-fold higher risk of 2-year mortality. We found a decreased eGFR was associated with a higher risk of death. Thus, RI was associated with higher rates of death. The most important finding of our study is that the inclusion of RI in the risk model improves the risk in female patients with STEMI in rural areas. We demonstrated hospitalization mortality in the RI group was $7.37 \%$. Another reported study showed a similar mortality rate of $7.69 \%$ [25]. It has also previously been confirmed that RI is an independent risk factor for poor prognosis in both the short and long term for female STEMI patients [26].

Renal dysfunction is an independent risk factor for death in patients with STEMI [27]. And patients with renal dysfunction have been shown to have a 6 to 11 fold higher in-hospital mortality rate compared to patients with normal renal function [8]. These patients more commonly developed low left ventricular ejection fraction, higher Killip class, cardiogenic shock, hemodynamic instability or malignant arrhythmia during admission [28]. Previous studies have also found that the risk of MACEs and cardiac death at both

Table 4 Univariate and multivariate analysis for prediction of in hospital mortality

\begin{tabular}{|c|c|c|c|c|c|c|}
\hline & \multicolumn{3}{|c|}{ Univariate } & \multicolumn{3}{|c|}{ Multivariate } \\
\hline & $\mathrm{HR}$ & $95 \% \mathrm{Cl}$ & $p$ value & $\mathrm{HR}$ & $95 \% \mathrm{Cl}$ & $p$ value \\
\hline \multicolumn{7}{|c|}{ eGFR ml/min/1.73 $\mathrm{m}^{2}$} \\
\hline$\geq 90$ & 1 & & & 1 & & \\
\hline $60-90$ & 0.942 & $0.653-1.131$ & 0.670 & 0.865 & $0.586-1.390$ & 0.220 \\
\hline$<60$ & 2.655 & $1.147-4.238$ & $0.003^{*}$ & 1.832 & $1.017-3.091$ & $0.033^{*}$ \\
\hline Age $\geq 75$ & 0.815 & $0.462-1.536$ & 0.504 & & & \\
\hline Diabetes & 0.893 & $0.601-1.072$ & 0.443 & & & \\
\hline Hypertension & 0.747 & $0.352-1.167$ & 0.340 & & & \\
\hline Hyperlipidemia & 0.86 & $0.317-1.053$ & 0.622 & & & \\
\hline Killip $\geq 2$ & 1.446 & $1.009-2.090$ & $0.047^{*}$ & 1.34 & $1.012-1.647$ & $0.018^{*}$ \\
\hline$E F<40 \%$ & 0.871 & $0.592-1.017$ & 0.317 & & & \\
\hline
\end{tabular}

$C$ confidence interval, eGFR estimated glomerular filtration rate, $E F$ ejection fraction, $H R$ hazard ratio ${ }^{*} p<0.05$ 
1 month and 1 year increased with lower eGFR [5]. Thus, the results of our study are in agreement with the previous research.

Comparison between the three groups showed that there were higher proportions of Killip class $\geq 2$, longer hospital stay, low LVEF values, high serum creatinine levels and cTnI peak in the RI group. The patients had larger myocardial infarction area and worse heart function. These differences may be related to the high mortality in the RI group. The Killip class is a useful prognostic tool for predicting in hospital mortality [29], and our results support this as the $\geq$ class 2 was also a predictive factor for in hospital mortality by multivariate analysis. Another recent study on RI in STEMI also found a higher Killip class was found with RI, and those patients also showed increased mortality with RI [30]. That study identified that RI patients were more likely to be female as well as older, and more likely to have diabetes mellitus, and hypertension [30]. Our study also identified age, diabetes and hypertension as likely to be higher in the RI group. Increased Killip score and lower LVEF were also significant in RI patients in a study evaluating the in-hospital outcome of patients with acute STEMI [31]. The mean LVEF was also decreased in the RI patients in our study. In terms of the 2-year mortality risk factors the RI group was found to be at much higher risk than the other two groups in this study and the only other predictive factor was age $\geq 75$ years. That was possibly an expected result [32].

We found there were no long-term standardized medication regimens after hospital discharge in the RI group. And dual antiplatelet therapy was used less in hospital in this group. Underuse of antiplatelet therapy, ACE inhibitors, $\beta$-blockers and statins might also be related to a reduced survival rate in patients with renal insufficiency as discontinuation of cardiac medication is itself associated with increased risk of mortality [33]. This may be another factor that is related to the high mortality in the RI group.

Renal dysfunction was associated with a 3 fold increased odds of discontinuation of antiplatelet drugs in patients with PCI [34]. Reasons for shorter duration of antiplatelet therapy and discontinuation observed in these studies and ours may include bleeding events, scheduled invasive procedures, psychiatric drug use, unemployment, patient choice and non-adherence and other medical events not specified including earlier mortality. It had been reported AMI patients with decreased GFR may receive less aggressive evidence-based therapies as those normal patients [35].

This study has some limitations as it was a prospective multicenter study with a limited sample size because of the limited number of rural patients. In the RI group the patients were not grouped further to eGFR $30-60 \mathrm{ml} / \mathrm{min} / 1.73 \mathrm{~m}^{2}$ and eGFR $<30 \mathrm{ml} / \mathrm{min} /$ $1.73 \mathrm{~m}^{2}$ to provide information on the severity of RI. We also were unable to provide a mean value of eGFR for the groups in this study because some of the raw data was lost, so we had to rely on the grouping ranges for our analysis. We did not include a control group without cardiac disease, to investigate whether these results relating to RI and mortality would be similar in a group of patients without STEMI. In addition, we did not address the question of a relationship between cardiac disease and kidney disease in these patients. Further analysis of more pathophysiological factors such as biomarkers for cardiac damage for example troponin would provide important information on the relationship between cardiac and kidney diseases.

\section{Conclusions}

In this real-world prospective multicenter study we found among female rural patients with STEMI after thrombolytic therapy or primary PCI therapy that RI was an independent risk factor for in-hospital and longterm mortality and was associated with poor prognosis. RI could be one of the better indices for clinical risk stratification.

\section{Availability of supporting data}

The data set supporting the results of this article are included within the article.

\section{Ethics approval and consent to participate}

This study was conducted in accordance with the declaration of Helsinki, and was conducted with approval from the Ethics Committee of China Medical University. Written informed consent was obtained from all participants.

\section{Consent for publication}

Not applicable.

\section{Appendix 1}

\section{Details of medication}

There were no significant difference in the administration of aspirin, ACEI/ARB, statins, beta -blockers, LWMH and traditional Chinese medicine between the three groups. But clopidogrel and dual antiplatelet therapy were lower in the RI group compared with the Normal group during hospitalization. The patients were followed up at 2 year. We found that clopidogrel, dual antiplatelet therapy, ACEI/ARB, statins, b-blocker were less used,but traditional Chinese medicine were more used in the RI group during follow-up (Appendix 1). 
Table 5 Medication use

\begin{tabular}{llll}
\hline & Normal group $(n=233)$ & Moderate group $(n=108)$ & Rl group $(n=95)$ \\
\hline In hospital & & 107 & 95 \\
Aspirin & 233 & 108 & 92 \\
Clopidogrel & 233 & 107 & 92 \\
dual antiplatelet therapy & 233 & 101 & 83 \\
ACEl/ARB & 221 & 89 & 77 \\
Statins & 205 & 98 & 79 \\
Beta blockers & 209 & 107 & 91 \\
Low molecular heparin & 230 & 61 & 59 \\
Traditional Chinese medicine & 157 & & 85 \\
At 2-year follow-up & & 84 & 8 \\
Aspirin & 176 & 29 & 8 \\
Clopidogrel & 61 & 29 & 7 \\
dual antiplatelet therapy & 60 & 3 & 9 \\
ACEl/ARB & 63 & 14 & 44 \\
Statins & 25 & 58 & 50 \\
Beta blockers & 155 & 41 & \\
Traditional Chinese medicine & 81 & &
\end{tabular}

\section{Abbreviations}

ACE: angiotensin-converting enzyme; ARB: angiotensin receptor antagonist; BMl: body mass index; Cl: confidence intervals; CIN: contrast-induced nephropathy; CKD-EPI: chronic kidney disease epidemiology collaboration; CKMB: creatine kinase MB; Ctni: cardiac troponin I; ECG: electrocardiogram; EF: ejection fraction; eGFR: estimated glomerular filtration rate; GUSTO: global use of strategies to open occluded coronary arteries; HDL: high-density lipoprotein; HR: hazard ratio; IQR: interquartile range; KDIGO: kidney disease: improving global outcomes; LDL: low-density lipoprotein; MACE: major adverse cardiac events; MDRD: modification of diet in renal disease; $\mathrm{PCl}$ : percutaneous coronary intervention; RI: renal insufficiency; RMI: recurrent myocardial infarction; Scr: serum creatinine; SD: standard deviation; STEMI: ST-segment elevation acute myocardial infarction; TIMI: thrombolysis in myocardial infarction; TVR: target vessel revascularization; WBC: white blood cell.

\section{Competing interests}

The authors declare that they have no competing interests.

\section{Authors' contributions}

YG participated in literature search, study design, data collection, data analysis, data interpretation and wrote the manuscript. DMJ, BZ, YJS, LNR and DDF participated in clinical examination and laboratory analysis. GXQ conceived of the study, and participated in its design and coordination and provided the critical revision. All authors read and approved the final manuscript.

\section{Acknowledgements}

None.

\section{Funding}

None.

\section{Author details}

${ }^{1}$ Department of Cardiology, First Affiliated Hospital of China Medical University, Shenyang, Liaoning 110001, China. Department of Cardiology, Dandong Center Hospital, Dandong, Liaoning 118000, China. ${ }^{3}$ Department of Cardiology, First Affiliated Hospital, Dalian Medical University, Dalian, Liaoning 116011, China. ${ }^{4}$ Department of Geriatric Cardiology, First Affiliated Hospital of China Medical University, Shenyang, Liaoning 110001, China.
Received: 7 August 2015 Accepted: 16 December 2015

Published online: 24 December 2015

\section{References}

1. Ojo A. Addressing the global burden of chronic kidney disease through clinical and translational research. Trans Am Clin Climatol Assoc. 2014;125: 229-43. discussion 43-6.

2. Fox CS, Muntner P, Chen AY, Alexander KP, Roe MT, Cannon CP, et al. Use of evidence-based therapies in short-term outcomes of ST-segment elevation myocardial infarction and non-ST-segment elevation myocardial infarction in patients with chronic kidney disease: a report from the National Cardiovascular Data Acute Coronary Treatment and Intervention Outcomes Network registry. Circulation. 2010;121(3):357-65.

3. Task Force on the management of STseamiotESoC, Steg PG, James SK, Atar D, Badano LP, Blomstrom-Lundqvist C, et al. ESC Guidelines for the management of acute myocardial infarction in patients presenting with ST-segment elevation. Eur Heart J. 2012:33(20):2569-619.

4. Said S, Hernandez GT. The link between chronic kidney disease and cardiovascular disease. J Nephropathol. 2014;3(3):99-104.

5. Anavekar NS, McMurray JJ, Velazquez EJ, Solomon SD, Kober L, Rouleau JL, et al. Relation between renal dysfunction and cardiovascular outcomes after myocardial infarction. N Engl J Med. 2004;351(13):1285-95.

6. Masoudi FA, Plomondon ME, Magid DJ, Sales A, Rumsfeld JS. Renal insufficiency and mortality from acute coronary syndromes. Am Heart J. 2004; 147(4):623-9.

7. Bae EH, Lim SY, Cho KH, Choi JS, Kim CS, Park JW, et al. GFR and cardiovascular outcomes after acute myocardial infarction: results from the Korea Acute Myocardial Infarction Registry. Am J Kidney Dis. 2012;59(6):795-802.

8. Kim JY, Jeong MH, Ahn YK, Moon JH, Chae SC, Hur SH, et al. Decreased glomerular filtration rate is an independent predictor of In-Hospital Mortality in patients with ST-segment elevation myocardial infarction undergoing Primary percutaneous coronary intervention. Korean Circ J. 2011:41(4):184-90.

9. Choi JH, Kim KL, Huh W, Kim B, Byun J, Suh W, et al. Decreased number and impaired angiogenic function of endothelial progenitor cells in patients with chronic renal failure. Arterioscler Thromb Vasc Biol. 2004;24(7):1246-52.

10. Shlipak MG, Heidenreich PA, Noguchi H, Chertow GM, Browner WS, McClellan MB. Association of renal insufficiency with treatment and outcomes after myocardial infarction in elderly patients. Ann Intern Med. 2002;137(7):555-62. 
11. Napoli C, Casamassimi A, Crudele V, Infante T, Abbondanza C. Kidney and heart interactions during cardiorenal syndrome: a molecular and clinical pathogenic framework. Future Cardiol. 2011;7(4):485-97.

12. Gulati M, Shaw LJ, Bairey Merz CN. Myocardial ischemia in women: lessons from the NHLBI WISE study. Clin Cardiol. 2012;35(3):141-8.

13. Pancholy SB, Shantha GP, Patel T, Cheskin LJ. Sex differences in short-term and long-term all-cause mortality among patients with ST-segment elevation myocardial infarction treated by primary percutaneous intervention: a meta-analysis. JAMA Intern Med. 2014;174(11):1822-30.

14. D'Ascenzo F, Gonella A, Quadri G, Longo G, Biondi-Zoccai G, Moretti C, et al. Comparison of mortality rates in women versus men presenting with ST-segment elevation myocardial infarction. Am J Cardiol. 2011;107(5):651-4

15. Zheng X, Dreyer RP, Hu S, Spatz ES, Masoudi FA, Spertus JA, et al. Age-specific gender differences in early mortality following ST-segment elevation myocardial infarction in China. Heart. 2014;101(5):349-55.

16. Jiang G, Wang D, Li W, Pan Y, Zheng W, Zhang H, et al. Coronary heart disease mortality in China: age, gender, and urban-rural gaps during epidemiological transition. Rev Panam Salud Publica. 2012;31(4):317-24.

17. Mehta RL, Kellum JA, Shah SV, Molitoris BA, Ronco C, Warnock DG, et al. Acute Kidney Injury Network: report of an initiative to improve outcomes in acute kidney injury. Crit Care. 2007;11(2):R31.

18. Levey AS, Stevens LA, Schmid CH, Zhang YL, Castro 3rd AF, Feldman HI, et al. A new equation to estimate glomerular filtration rate. Ann Intern Med. 2009; 150(9):604-12.

19. Kidney Disease: Improving Global Outcomes (KDIGO) Acute Kidney Injury Work Group. KDIGO Clinical Practice Guideline for Acute Kidney Injury. Kidney Int Suppl. 2012;2:1-138.

20. Levine GN, Bates ER, Blankenship JC, Bailey SR, Bittl JA, Cercek B, et al. 2011 ACCF/AHA/SCAI Guideline for Percutaneous Coronary Intervention: a report of the American College of Cardiology Foundation/American Heart Association Task Force on Practice Guidelines and the Society for Cardiovascular Angiography and Interventions. Circulation. 2011;124(23): e574-651.

21. Consultation WHOE. Appropriate body-mass index for Asian populations and its implications for policy and intervention strategies. Lancet. 2004; 363(9403):157-63.

22. Rihal CS, Textor SC, Grill DE, Berger PB, Ting HH, Best PJ, et al. Incidence and prognostic importance of acute renal failure after percutaneous coronary intervention. Circulation. 2002;105(19):2259-64.

23. An international randomized trial comparing four thrombolytic strategies for acute myocardial infarction. The GUSTO investigators. N Engl J Med. 1993; 329(10):673-82.

24. Barrett BJ, Parfrey PS. Clinical practice. Preventing nephropathy induced by contrast medium. N Engl J Med. 2006;354(4):379-86.

25. Liu Y, Gao L, Xue Q, Yan M, Chen P, Wang Y, et al. Impact of renal dysfunction on long-term outcomes of elderly patients with acute coronary syndrome: a longitudinal, prospective observational study. BMC Nephrol. 2014;15:78.

26. Go AS, Chertow GM, Fan D, McCulloch CE, Hsu CY. Chronic kidney disease and the risks of death, cardiovascular events, and hospitalization. N Engl J Med. 2004;351(13):1296-305.

27. Rodrigues FB, Bruetto RG, Torres US, Otaviano AP, Zanetta DM, Burdmann EA. Effect of kidney disease on acute coronary syndrome. Clin J Am Soc Nephrol. 2010;5(8):1530-6.

28. Parikh CR, Coca SG, Wang Y, Masoudi FA, Krumholz HM. Long-term prognosis of acute kidney injury after acute myocardial infarction. Arch Intern Med. 2008;168(9):987-95.

29. de Mello BH, Oliveira GB, Ramos RF, Lopes BB, Barros CB, Carvalho Ede O, et al. Validation of the Killip-Kimball classification and late mortality after acute myocardial infarction. Arq Bras Cardiol. 2014;103(2):107-17.

30. Sabroe JE, Thayssen P, Antonsen L, Hougaard M, Hansen KN, Jensen LO. Impact of renal insufficiency on mortality in patients with ST-segment elevation myocardial infarction treated with primary percutaneous coronary intervention. BMC Cardiovasc Disord. 2014;14:15

31. Pasha K, Ali MA, Habib MA, Debnath RC, Islam MN. In-hospital outcome of patients with acute STEMI with impaired renal function. Mymensingh Med J. 2011;20(3):425-30

32. Newell MC, Henry JT, Henry TD, Duval S, Browning JA, Christiansen EC, et al. Impact of age on treatment and outcomes in ST-elevation myocardial infarction. Am Heart J. 2011;161(4):664-72.
33. Ivers NM, Schwalm JD, Grimshaw JM, Witteman H, Taljaard M, Zwarenstein $M$, et al. Delayed educational reminders for long-term medication adherence in ST-elevation myocardial infarction (DERLA-STEMI): protocol for a pragmatic, cluster-randomized controlled trial. Implement Sci. 2012;7:54

34. Ferreira-Gonzalez I, Marsal JR, Ribera A, Permanyer-Miralda G, Garcia-Del Blanco B, Marti G, et al. Background, incidence, and predictors of antiplatelet therapy discontinuation during the first year after drug-eluting stent implantation. Circulation. 2010;122(10):1017-25.

35. Coca SG, Krumholz HM, Garg AX, Parikh CR. Underrepresentation of renal disease in randomized controlled trials of cardiovascular disease. JAMA. 2006:296(11):1377-84.

\section{Submit your next manuscript to BioMed Central and we will help you at every step:}

- We accept pre-submission inquiries

- Our selector tool helps you to find the most relevant journal

- We provide round the clock customer support

- Convenient online submission

- Thorough peer review

- Inclusion in PubMed and all major indexing services

- Maximum visibility for your research

Submit your manuscript at www.biomedcentral.com/submit
Biomed Central 